\title{
Inflammatory signs and epileptic crisis in patients admitted in an emergency unit
}

\author{
Sinais inflamatórios e crise epiléptica em pacientes \\ admitidos em unidade de emergência \\ Signos inflamatorios y crisis epiléptica en pacientes \\ admitidos en una unidad de emergencia
}

\section{Edson Fernando Muller Guzzo \\ Diane Bressan Pedrini ${ }^{b}$ Márcia Koja Breigeironc}

How to cite this article: Guzzo EFM, Pedrini DB, Breigeiron MK. Inflammatory signs and epileptic crisis in patients admitted in an emergency unit. Rev Gaúcha Enferm. 2020;41:e20190074. doi: https://doi.org/10.1590/19831447.2020.20190074 aniversidade Federal do Rio Grande do Sul (UFRGS), Instituto de Ciências Básicas da Saúde, Programa de Pós-graduação em Farmacologia eTerapêutica. Porto Alegre, Rio Grande do Sul, Brasil.

b Universidade Federal do Rio Grande do Sul (UFRGS), Faculdade de Medicina, Programa de Pós-Graduação em Saúde da Criança e do Adolescente. Porto Alegre, Rio Grande do Sul, Brasil.

c Universidade Federal do Rio Grande do Sul (UFRGS), Escola de Enfermagem, Departamento de Enfermagem Materno-Infantil. Porto Alegre, Rio Grande do Sul, Brasil.

\section{ABSTRACT}

Objective: To evaluate inflammatory signs presented in medical records of patients with a main diagnosis of epileptic seizures, admitted in an emergency unit.

Method: Cross-sectional and retrospective study. The sample was composed of 191 medical records, from children, adolescents, adults, and elders, with a clinical diagnosis of epileptic seizures, admitted between June 2016 and June 2017 at the emergency unit of a hospital in Porto Alegre/RS.

Results: The prevalent inflammatory signs were tachypnea (33.5\%) and/or fever (27.2\%) associated with leukocytosis ( $P=0.030)$. Children/adolescents had seizures less frequently $(P=0.010)$ and these were due to fever $(P=0.000)$. Adults presented seizures more frequently $(P=0.006)$, which were related to medication/intoxication $(P=0.000)$. In elders, seizures occurred due to metabolic or circulatory abnormalities $(P=0.000)$, less often due to fever $(P=0.005)$.

Conclusion: Seizures are related to fever and tachypnea, being caused by different etiologies according to age, being more frequent in adults. Fever is related to leukocytosis, regardless of age.

Keywords: Seizures. Emergency nursing. Inflammation. Emergency medical services.

\section{RESUMO}

Objetivo: Avaliar os sinais inflamatórios registrados em prontuários de pacientes com diagnóstico principal de crise epiléptica, admitidos em unidade de emergência.

Método: Estudo transversal, retrospectivo. Amostra composta por 191 prontuários de pacientes pediátricos, adolescentes, adultos e idosos, com diagnóstico clínico de crise epiléptica, admitidos entre junho de 2016 a junho de 2017, na unidade de emergência de um hospital de Porto Alegre/RS.

Resultados: Prevalência do relato de taquipneia (33,5\%) e/ou febre (27,2\%) como sinais inflamatórios, estando febre relacionada à leucocitose $(P=0,030)$. Crianças/adolescentes tiverem crises menos frequentes $(P=0,010)$ e de origem febril $(P=0,000)$. Adultos apresentaram maior número de eventos ( $P=0,006)$, provocados por medicações/intoxicações $(P=0,000)$. Nos idosos, crises ocorreram por distúrbios metabólicos/circulatórios ( $P=0,000)$, com menor ocorrência de febre $(P=0,005)$.

Conclusão: Crises epilépticas estão relacionadas à presença de febre e taquipneia, apresentando diferentes etiologias conforme faixa etária, com maior frequência de ocorrência entre adultos. Febre está relacionada à leucocitose, independentemente da idade.

Palavras-chave: Convulsões. Enfermagem em emergência. Inflamação. Serviços médicos de emergência.

\section{RESUMEN}

Objetivo: Evaluar signos inflamatorios registrados en prontuarios de pacientes con diagnóstico principal de crisis epilépticas, admitidos en unidad de emergencia.

Método: Estudio transversal, retrospectivo. Muestra compuesta por 191 prontuarios de pacientes pediátricos, adolescentes, adultos y ancianos, diagnosticados con crisis epilépticas, admitidos entre junio de 2016 a junio de 2017 en unidad de emergencia de un hospital de Porto Alegre/RS.

Resultados: Prevalencia del taquipnea $(33,5 \%)$ y/o fiebre $(27,2 \%)$ como signos inflamatorios, fiebre relacionada a leucocitosis $(P=0,030)$. Niños/adolescentes tienen crisis menos frecuentes $(P=0,010)$ de origen febril $(P=0,000)$. Los adultos presentaron mayor número de eventos $(P=0,006)$, provocados por medicamentos/intoxicaciones $(P=0,000)$. En ancianos, crisis ocurrieron debido a disturbios metabólicos/circulatorios $(P=0,000)$, menor ocurrencia de fiebre $(P=0,005)$.

Conclusión: Crisis epilépticas están relacionadas a fiebre y taquipnea, presentando diferentes etiologías según grupo de edad, con mayor ocurrencia entre adultos. Fiebre relacionada con el leucocitosis, independientemente de la edad.

Palabras clave: Convulsiones. Enfermería de urgencia. Inflamación. Servicios médicos de urgencia. 


\section{口INTRODUCTION}

Epilepsy is a neurological disease that affects about fifty million people around the world. Epileptic seizures are characterized by a paroxysmal alteration in brain function resulting from abnormal electrical discharges from neurons. Clinically, they may manifest in various ways: alteration or loss of consciousness, abnormal motor activity, behavioral changes, sensory disturbances, autonomic or other manifestations according to the area of the brain affected. The following conditions are cited as the etiology of epileptic seizures: ischemic stroke, parasitic diseases, traumatic brain injury, cancer, cerebrovascular malformation, inflammation, among other causes ${ }^{(1)}$.

The International League Against Epilepsy (ILAE) Commission on Classification and Terminology has classified forms of epileptic seizures and epilepsy. Nowadays, the simplified classification adopted by ILEA classifies epileptic seizures into focal onset, generalized onset, unknown onset, or unclassified seizures ${ }^{(1)}$.

In epilepsy and other neurological diseases such as Parkison's disease, Alzheimer's, sclerosis and cerebral ischemia there is evidence of a high number of inflammatory mediators in brain tissues, showing the role of inflammation in the pathophysiology of such diseases ${ }^{(2)}$. Inflammation is the series of tissue changes suffered by the organism due to some injury caused by bacteria, trauma, chemical agents or any other phenomenon. These changes involve the release of various substances by the damaged tissues, that are capable of causing changes in adjacent uninjured tissues ${ }^{(3)}$.

There are several clinical manifestations of the inflammatory process, where fever is the first sign of systemic inflammation, and may also increase heart rates ( $>90$ beats/ $\mathrm{min}$ ) and respiratory rates ( $>20$ movements/min or carbon dioxide partial pressure - $\left.\mathrm{PaCO}_{2}<32 \mathrm{mmHg}\right)^{(4)}$.

Observation of the typical signs and symptoms of the inflammatory process and laboratory tests are of great importance for the evaluation of the seizure process, both in the follow-up of the patient diagnosed with epilepsy and for those who are suffering the first seizure. Laboratory tests help in clinical decision-making, especially when the epileptic seizure took place in an out-of-hospital setting and was not observed by qualified professionals. White blood cell count and C-reactive protein (CRP) measurement are often used to monitor inflammatory profile of the body and the effectiveness of anti-inflammatory therapy. Other tests such as erythrocyte sedimentation rate (ESR) and ferritin and iron levels are influenced by the presence of the inflammatory process. Blood culture, when positive, may indicate the etiological factor responsible for the increase in inflammatory profile of the patient ${ }^{(5)}$.

Clinically, in epilepsy and epileptic seizures, the role of inflammation in pathophysiology is hypothetical; however, the inflammatory process can act both at the onset of a crisis and in maintaining an epileptogenic process. Factual evidence of a relationship between epileptic seizures and inflammatory processes has been found, such as: good clinical response to the use of anti-inflammatory drugs as a form of complementary therapy in cases of epilepsy refractory to conventional treatments; presence of inflammatory markers in brain tissues of patients; connection of abnormal immune responses to seizures; and the fact that fever and common infections can lead to epileptic seizures ${ }^{(6)}$

There are no studies specifying the signs and symptoms related to the inflammatory process in patients with a history of epileptic seizure, which is something to be explored. Thus, knowing the clinical and laboratory manifestations and the inducing processes of epileptic seizures can favor the performance of actions of care that meet the needs of patients, based on their clinical complaints, laboratory evidence, and previous clinical history.

Considering that understanding the signs and symptoms related to the inflammatory process in patients with a history of epileptic seizures enables qualified nursing care, this study was guided by the question: how do inflammatory signs manifest in patients with epileptic seizures?

Therefore, this study aimed to evaluate the inflammatory signs presented in the medical records of patients with a main diagnosis of epileptic seizure admitted to an emergency unit.

\section{METHOD}

Cross-sectional, quantitative and retrospective study. The study population consisted of 270 patients admitted to the emergency department of a general hospital in the southern region of Brazil, from June 2016 to June 2017, with the main diagnosis of epileptic seizure. This list was conceded by the data processing department of the hospital. Inclusion criteria were: pediatric, adolescent, adult, and elderly patients with a clinical diagnosis of epileptic seizure (according to medical diagnoses) and who had an electronic record of the evolution created by the nurse or physician who was the first to attend the patient in the emergency department.

For the sample calculation, an error of $4 \%$, a confidence interval of $95 \%$ and a sample loss of $20 \%$ were considered. Thus, a sample with 197 records was estimated. From these, 
6 (six) medical records were excluded because they did not present an electronic record of the care provided by nurses or doctors, but only by other health professionals, totaling a final sample of 191 patient records in accordance to the inclusion criteria.

Data were collected in August 2017, retrospectively, from the material in the electronic medical records of patients admitted to the emergency unit of the hospital of reference. The records made by doctors and nurses within the first 48 hours of hospitalization of the patient were considered, excluding manual records and those made after transferring the patient to another hospital sector.

The medical records were made available by the Medical and Statistical Filing Service (SAME) of the institution, according to the ordering of the list granted by the data processing department. Data were extracted from medical records and passed on to an instrument that contained the study variables.

The study variables related to patient (age, gender, self-declared color, city of origin, and years of formal education), epileptic seizure (previous diagnoses, type, number of episodes in 24 hours, impairment of consciousness, and etiology), home therapy (pharmacological and non-pharmacological, such as the use of teas and alternative and complementary practices), inflammatory signs (fever — equal to or higher than $37.8^{\circ} \mathrm{C}$, change in respiratory rates, ganglion engorgement, presence of tissue lesions, contaminated secretions, and laboratory alterations such as: leukocytosis, CRP activation, increased ESR, and positive blood culture), and secondary clinical diagnoses were analyzed. Regarding their age, individuals were classified as children / adolescents (up to 17 years, 11 months and 29 days), adults (18 years up to 59 years, 11 months and 29 days), and elderly (60 years old or older). When considering the changes in respiratory rate and laboratory tests, the age groups of the sample were respected.

The Statistical Package for the Social Sciences (SPSS) version 18.0 was used for data tabulation. The results were presented as frequency, mean and standard deviation, median and interquartile range (25-75). For statistical analysis, the chi-square test $(P<0.05)$ was used.

Ethical and legal research precepts were ensured, according to Resolution 466/12 of the National Health Council (BRASIL, 2012). The study was approved by the Research Ethics Committee of the institution involved under CAAE No. 67897617.4.0000.5327.

The study originated from the monograph ${ }^{(7)}$ entitled "Inflammatory signs and epileptic seizure in patients admitted to an emergency unit".

\section{$\square$ RESULTS}

The sample consisted of 191 medical records of patients with the main clinical diagnosis of epileptic seizure.

There was a predominance of male, self-declared white, from the capital of the state and with incomplete elementary school. The average age of the patients was 40 (8-65) years of age. There was no association between the type of seizure or the number of seizures within 24 hours with the sociodemographic characteristics evaluated $(P>0.05)$. The sociodemographic characterization of the sample is described in Table 1.

Epileptic seizures in previous hospitalizations were described in 127 (66.4\%) patient records, from which 57 (29.8\%) had a diagnosis of epilepsy with prescribed pharmacological treatment being used at home.

Hospitalization at the emergency unit due to a first epileptic seizure situation occurred in 63 (32.9\%) patients, with a significant difference for the elderly ( $\geq 60$ years) when compared to children / adolescents and adults ( $P=0.010)$.

Regarding the type of epileptic seizure, generalized seizures were recorded in 110 (57.5\%) records, followed by focal seizures in 30 (15.7\%) cases. The generalized seizure of the tonic-clonic type occurred in 77 (40.3\%) patients.

Loss of consciousness during the epileptic seizures was described in 113 (84\%) records and was related to the occurrence of generalized seizures $(P=0.000)$.

The occurrence of 1-2 epileptic seizures in patients within 24 hours was described in 154 (80.6\%) records, with prevalence among children / adolescents $(P=0.006)$. While 3-4 epileptic seizures were recorded in 30 (15.7\%) patients, with a predominance in adults ( $P=0.006)$. From this total, 7 (3.7\%) patients had seven or more epileptic seizures within 24 hours.

Regarding the etiology of the epileptic seizure, there was a prevalence of structural causes of the Central Nervous System (CNS) in 59 (30.9\%) records; from these, the diagnosis of epilepsy was the cause of epileptic seizure in 39 (66.1\%) cases and cancer/metastases in 19 (32.2\%) cases. Other etiologies for epileptic seizures were: circulatory disorders and infections/infestations or both in 26 (13.8\%), metabolic disorders in 11 (5.8\%) and fever in 17 (9.0\%). The main metabolic disorders responsible for triggering epileptic seizures were: hypocalcemia, uremia and liver failure. Fever was the most prevalent etiological factor of epileptic seizures in children/adolescents, while in the elderly it was the metabolic/ circulatory disorders, and in adults, medications/intoxication and psychoactive agents $(P=0.000)$. Among the circulatory disorders, strokes were reported in 20 (76.9\%) records, followed by brain hypoxia, hypertensive encephalopathy, 
Table 1 - Sociodemographic characterization of patients with a main clinical diagnosis of epileptic seizures admitted to an emergency unit of a hospital in southern Brazil, according to medical records. Porto Alegre, RS, Brazil, 2017

\begin{tabular}{lll}
$\begin{array}{l}\text { Sociodemographic } \\
\text { characteristics }\end{array}$ & n (n) & $\%$ \\
Gender & $101(191)$ & 52.9 \\
\hline Male & $90(191)$ & 47.1 \\
\hline Female & \\
\hline Age group (years) & $66(191)$ & 34.6 \\
\hline$<18$ & $67(191)$ & 35.1 \\
\hline 18 H60 & $58(191)$ & 30.3 \\
\hline$>60$ &
\end{tabular}

\section{Self-declared skin color}

\begin{tabular}{lcc}
\hline White & $151(191)$ & 79.1 \\
\hline Brown & $21(191)$ & 11.0 \\
\hline Black & $19(191)$ & 9.9 \\
\hline
\end{tabular}

\section{Place of origin}

\begin{tabular}{lll}
\hline Capital & $105(191)$ & 55.0 \\
\hline Interior & $86(191)$ & 45.0 \\
\hline
\end{tabular}

Years of formal education

\begin{tabular}{lcc}
\hline $1 H^{4}$ & $55(110)$ & 50.0 \\
\hline $5 \dashv 7$ & $25(110)$ & 22.7 \\
\hline $7 \dashv 12$ & $28(110)$ & 25.5 \\
\hline$\geq 12$ & $2(110)$ & 1.8 \\
\hline
\end{tabular}

Source: Research data, 2017

$\mathrm{n}=$ sample; $\%$ = relative frequency

intracranial hemorrhage and other pathologies that represented 6 (23.1\%) cases.

The continuous use of pharmacological therapy was reported in 146 (76.4\%) records. Among these, anticonvulsants were reported in 108 (73.9\%) cases, being the group of drugs with the highest record. There was no record of non-pharmacological treatment in the medical records (Table 2). A preventive use of anticonvulsants did not change the number of epileptic seizures within 24 hours ( $P=0.290)$. In addition, there was no difference regarding the type of seizure and use of pharmacological therapy at home ( $P=0.355$ ).

Among the inflammatory signs, tachypnea was the most prevalent, being recorded 64 (33.5\%) times. Bradycardia was
Table 2 - Associated and home use Pharmacological therapy by patients with a main clinical diagnosis of epileptic seizure, admitted to an emergency unit of a hospital in the southern region of Brazil, according to medical records. Porto Alegre, RS, Brazil, 2017

\begin{tabular}{|c|c|c|}
\hline Main drug & Associated drug & n (\%) \\
\hline \multicolumn{3}{|l|}{ Anticonvulsant } \\
\hline & None & $91(47.6)$ \\
\hline & Anti-bacterial & $11(5.7)$ \\
\hline & Immunosuppressive & $6(3.14)$ \\
\hline Anti-bacterial & & $19(9.9)$ \\
\hline Immunosuppressants & & $10(5.2)$ \\
\hline NSAIDs* & & $5(2.61)$ \\
\hline Glucocorticoids & & $4(2)$ \\
\hline
\end{tabular}

Source: Research data, 2017

$n=$ sample; $\%$ = relative frequency; ${ }^{*}$ non-steroidal anti-inflammatory drugs.

recorded in 1 (0.5\%) medical chart, and eupnea was recorded in 125 (66\%). Fever was found in 52 (27.2\%) records and normothermia in 139 (72.8\%). Its presence was not associated with seizures in the elderly $(P=0.003)$. Febrile seizures were reported in 17 (32.7\%) cases. Records of tissue lesions were present in 11 (5.8\%) charts and contaminated secretions in 29 (15.2\%). The presence of inflammatory signs was not associated with pharmacological therapies used at home $(P>0.05)$. Among the inflammatory signs recorded, there was a prevalence of tachypnea and / or fever in medical records of self-reported black patients, compared to white and brown ones $(P=0.031)$.

The white blood cell count was the most performed laboratory test, followed by the quantitative PCR test and the VSH test. Other laboratory tests were blood culture and serum levels of ferritin and/or iron. Among the patients who collected leukograms, 64 (33.5\%) presented leukocytosis, which was associated with the presence of fever ( $P=0.022)$. The laboratory test results can be found in Table 3 .

From the total, 122 (63.9\%) had records of previous secondary diagnoses besides epileptic seizures. Of these diagnoses, the most prevalent were: Systemic Arterial Hypertension and Diabetes Mellitus, with 66 (34.5\%) and 25 (13\%) records, respectively. Other pathologies reported include hypothyroidism ( $8-4.1 \%)$, asthma (5 - 2.6\%), neurodegenerative diseases $(6-2.6 \%)$, and obesity $(6-2.6 \%)$. There was not a relation between the secondary diagnosis in the records and an increase in the number of seizures within 24 hours or to a specific type of seizure $(P>0.05)$. 
Table 3 - Laboratory tests of patients with a main clinical diagnosis of epileptic seizures admitted to an emergency unit of a hospital in southern Brazil, according to medical records. Porto Alegre, RS, Brazil, 2017

\begin{tabular}{llc} 
Laboratory test & Result & n (\%) \\
Leucogram & & \\
& Performed & $160(100)$ \\
& Leucocytosis & $73(45.6)$ \\
& Reference value* & $87(54.4)$ \\
\hline PCR & Performed & $103(100)$ \\
& PCR activation & $71(68.9)$ \\
& Reference value* & $32(31.1)$ \\
\hline VHS & & \\
& Performed & $93(100)$ \\
& VHS increase & $39(41.9)$ \\
& Reference value* & $54(58.1)$ \\
\hline Blood culture & & \\
& Performed & $57(100)$ \\
& Positive & $10(17.5)$ \\
& Negative** & $47(82.5)$ \\
\hline Serum iron & & \\
& Performed & $7(100)$ \\
& Reduced & $2(28.5)$ \\
& Reference value* & $5(71.5)$ \\
\hline
\end{tabular}

Source: Research data, 2017

* Reference values according to the age of the individuals; ${ }^{* *}$ Negative blood culture represents the absence of bacterial growth in the sample.

\section{口DISCUSSION}

The prevalent inflammatory signs in patients diagnosed with epileptic seizure admitted to the emergency unit were tachypnea and/or fever, with a relation between leukocytosis and fever. There was a predominance of male adults, self-declared white and from the capital.

Children/adolescents presented less seizures in 24 hours due to fever; while adults had a higher number of seizures, and older people had a lower occurrence of fever. In adults, the main etiology of the seizures was medication / intoxication. Admission to the emergency unit due to a first diagnosis of epileptic seizure was prevalent in the elderly, among whom metabolic / circulatory disorders were the factors associated etiology. The outcome loss of consciousness was related to generalized seizures.

As for the results of laboratory tests characteristic of the inflammatory process, there was CRP activation, leukocytosis and increase in ESR, however without associations with the presence of fever or tachypnea.

Records of inflammatory signs in the medical records of patients with a main diagnosis of epileptic seizure allowed the identification of the demographic profile of patients who are treated in an emergency unit: from both sexes, diverse of age groups, coming from the state capital, self-declared white, with few years formal education.

Previous diagnoses of epilepsy were predominant in the admission of patients due to epileptic seizures, evidencing an existing difficulty in controlling new epileptic seizures in patients with a clinical history. Among the age groups studied, patients over 65 years of age presented the most epileptic seizures without a previous clinical history, due to the physiological processes of aging, which also means they are very affected by epileptic seizures ${ }^{(8)}$.

There were cases of loss of consciousness during generalized seizures, an outcome rarely found in partial seizures. Corroborating this result and in accordance to the simplified classification adopted by the ILEA for epileptic seizures and epilepsy, there was loss of consciousness in the vast majority of generalized seizures and in some cases of focal epileptic seizures ${ }^{(1)}$.

The main etiology for the epileptic seizures was structural alteration of the CNS (epilepsies and cancer). A study that described the causal prevalence of epileptic seizures in the elderly showed that epilepsy and epileptic seizures have an etiological association with stroke, cancer, and dementias(9).

Besides structural alterations of the CNS, there were also occurrences of epileptic seizures due to metabolic and vascular etiologies. This result corroborates a review article on diagnosis and treatment of epilepsy in old age ${ }^{(10)}$, in which the authors describe that the most common cause is cerebrovascular disease.

Among adults there was a predominance of epileptic seizures caused by medication / intoxication and the use of licit and illicit drugs, which may be explained by the greater exposure of this group to these substances. This assumption comes from a study that identified the profile of crack and / or similar users in the Brazilian population, where it was seen that users are mostly young adults, with a mean age of 30.3 years ${ }^{(11)}$.

Epileptic seizures taking place within 24 hours in children/ adolescents are less frequent than in adults and elderly, regardless of etiology. In addition, fever was a prevalent cause for epileptic seizures in children / adolescents. In children, the fact that fever episodes cause epileptic seizures may be explained by their higher CNS sensitivity, making this population more susceptible to febrile seizures. This is a benign and self-limiting diagnosis, affecting from $2 \%$ to $5 \%$ 
of children and triggered by genetic and environmental factors ${ }^{(12)}$. Thus, it can be inferred that the number of episodes of epileptic seizure can be reduced by treating the cause, in this case, the fever.

Fever and tachypnea were described in most of the medical records, which are nonspecific signs that may take place in several pathologies, being present before the occurrence of epileptic seizures in epileptic patients. The relation found in the present study between the occurrence of fever concomitant with leukocytosis, during and after epileptic seizures, has been discussed in a previous ${ }^{(12)}$. The authors described increased body temperature and leukocytosis as seizure-induced inflammatory responses in patients diagnosed with epileptic seizures. In the same study, the incidence of fever and leukocytosis occurred simultaneously in $9.4 \%$ of the sample, being the inflammatory signs of higher prevalence ${ }^{(13)}$.

Fever episodes were uncommon among the elderly in this study. Less cases of fever in the elderly is an expected result, since typical signs such as fever and leukocytosis may be absent due to the pathophysiological process of aging ${ }^{(14)}$.

The occurrence of tachypnea during an epileptic seizure may be due to metabolic changes (release of catecholamines and prolactin) that activate muscle contraction in the sympathetic nervous system and consequently increase the need for local oxygen. This process is compensated by temporary mechanisms, which may increase the respiratory rate ${ }^{(15)}$.

In one of the medical records, ganglion engorgement was described, while few recorded skin conditions. Considering that ganglion engorgement and skin lesions are related to inflammation, the lack of these records made it difficult to do a more comprehensive analysis of the inflammatory process, restricting it to signs of tachypnea and fever. A recent study reports levels of non-compliance in medical records of $61 \%$, and as high as $65 \%$ regarding nursing staff records, showing that incomplete records are common in health institutions ${ }^{(16)}$.

Concomitant pathologies found in medical records were: systemic arterial hypertension and Diabetes Mellitus. Systemic arterial hypertension is associated with inflammation, although the relationship between them is unclear. Diabetes Mellitus is characterized as a manifestation of the body's inflammatory response, reiterating the close connection between the inflammatory process and this pathology ${ }^{(17)}$.

Most patients whose CRP was evaluated had this protein activated, without relation to the type of epileptic seizure. It has been reported that the occurrence of frequent generalized motor seizures is correlated with high CRP levels ${ }^{(18)}$.

Home use of pharmacological therapy has been described in many medical records, with anticonvulsants being the most used group. The use of pharmacological therapies in patients diagnosed with epilepsy is intended to provide the patient with a lifestyle that is as close to normal as possible, preferably seizure-free and with minimal medication side effects. However, in many cases, the patient continues to have seizures despite the use of prescribed anticonvulsants, impairing their daily activities ${ }^{(19)}$. No records of non-pharmacological therapy use, such as alternative / complementary methods to the treatment of epilepsy were found.

Understanding the inflammatory processes related to epileptic seizures based on the records of health professionals made it possible to identify the profile of patients admitted to an emergency unit due to epileptic seizures and the characteristics of this pathology. However, the present study has as a limitation in the fact that it was performed in a single institution, despite its being a reference in the southern region of Brazil. Studies that enable multicenter observations would be necessary to validate the results found.

The results of this study may contribute to a better understanding of the pathophysiological mechanisms of epileptic seizure, since the relationship between epileptic seizures and inflammatory processes is still poorly discussed and can be better explored.

\section{- CONCLUSIONS}

The study showed a prevalence of tachypnea and fever as inflammatory signs, being the fever related to leukocytosis. CNS structural alterations, followed by circulatory disorders, infections/intoxications, metabolic disorders and fever were causes of epileptic seizure in the sample analyzed, whose prevalence differed according to age group. Children/adolescents are more affected by febrile epileptic seizures, adults' seizures are related to medication/intoxication and use of licit and illicit drugs, and seizures in the elderly are related to metabolic/circulatory disorders. In the elderly, the presence of fevers was not a prominent inflammatory sign. The number of epileptic seizures within 24 hours was different between age groups, with adults having a higher number of episodes. These results contribute to understanding the relations between inflammatory signs and epileptic seizures, a theme still poorly understood. The knowledge of health professionals about inflammatory signs (tachypnea and fever), changes in leukograms, and causes of epileptic seizure, according to age group, contributes to the search for strategies to prevent new seizures, qualifying care and providing individualized care to patients. 


\section{REFERENCES}

1. Fisher RS, Cross JH, French JA, Higurashi N, Hirsch E, Jansen FE, et al. Operational classification of seizure types by the International League Against Epilepsy: position paper of the ILAE Commission for Classification and Terminology. Epilepsia. 2017;58(4):522-30. doi: https://doi.org/10.1111/epi.13670

2. Stephenson J, Nutma E, van der Valk P, Amor S. Inflammation in CNS neurodegenerative diseases. Immunology. 2018;154(2):204-19. doi: https:// doi.org/10.1111/imm.12922

3. Cavaillon J, Singer M. Inflammation: from molecular and cellular mechanisms to the clinic. Nova Jersey: John Wiley\& Sons; 2018.

4. Kokotovic D, Burcharth J, Helgstrand F, Gögenur I. Systemic inflammatory response after hernia repair: a systematic review. Langenbeck's Arch Surg. 2017;402(7):1023-37. doi: https://doi.org/10.1007/s00423-017-1618-1

5. Wallach JB. Interpretation of diagnostic tests. $10^{\text {th }}$ ed. Philadelphia: Lippincott Williams \& Wilkins; 2015.

6. Marchi N, GranataT, Janigro D. Inflammatory pathways of seizure disorders. Trends Neurosci. 2014;37(2):55-65. doi: https://doi.org/10.1016/j.tins.2013.11.002

7. Guzzo, EFM. Sinais inflamatórios e crise epiléptica em pacientes admitidos em unidade de emergência [monografia]. Porto Alegre (RS): Universidade Federal do Rio Grande do Sul, Escola de Enfermagem; 2017.

8. Kamitaki BK, Choi H. Epilepsy in the elderly: risk factors and management approaches. Curr Geriatri Rep. 2018;7(1):12-8. doi: https://doi.org/10.1007/ s13670-018-0235-3

9. Assis TR, Bacellar A, Costa G, Nascimento 0J. Etiological prevalence of epilepsy and epileptic seizures in hospitalized elderly in a Brazilian tertiary center Salvador - Brazil. Arq Neuro-Psiquiatr. 2015;73(2):83-9. doi: https://doi. org/10.1590/0004-282X20140217

10. Acharya JN, Acharya VJ. Epilepsy in the elderly: special considerations and challenges. Ann Indian Acad Neurol. 2014;17(1):18-26. doi: https://doi. org/10.4103/0972-2327.128645

11. Bastos FIPM, Bertoni N, organizadores. Pesquisa nacional sobre o uso de crack: quem são os usuários de crack e/ou similares do Brasil? quantos são nas capitais brasileiras? Rio de Janeiro: Fiocruz/lcict; 2014 [cited 2019 Jan 20]. Available from: https://www.arca.fiocruz.br/handle/icict/10019
12. Ye M, Yang J, Tian C, Zhu Q, Yin L, Jiang S, et al. Differential roles of $\mathrm{Na}_{12}$ and $\mathrm{Na}_{16}$ in regulating neuronal excitability at febrile temperature and distinct contributions to febrile seizures. Sci Rep. 2018;8(1):1-15. doi: https://doi. org/10.1038/s41598-017-17344-8

13. Sohn HS, Kim SK, Lee SY. Inflammatory markers associated with seizures. Epileptic Disord. 2016;18(1):51-7. doi: https://doi.org/10.1684/ epd.2016.0794

14. Oliveira CP, Santos IMG, Rocca AR, Dobri GP, Nascimento GD. Perfil epidemiológico de pacientes idosos atendidos em um pronto-socorro de hospital universitário brasileiro. Rev Med (São Paulo). 2018;97(1):44-50. doi: https://doi.org/10.11606/issn.1679-9836.v97i1p44-50

15. Nass RD, Sassen R, Elger CE, Surges R. The role of postictal laboratory blood analyses in the diagnosis and prognosis of seizures. Seizure. 2017;47:51-65. doi: https://doi.org/10.1016/j.seizure.2017.02.013

16. Alves KYA, Oliveira PTC, Chiavone FBT, Barbosa ML, Saraiva COPO, Martins CCF, et al. Patient identification in the records of health professionals. Acta Paul Enferm. 2018;31(1):79-86. doi: https://doi.org/10.1590/19820194201800012

17. Dinh QN, Drummond GR, Sobey CG, Chrissobolis S. Roles of inflammation, oxidative stress, and vascular dysfunction in hypertension. BioMed Res Int. 2014;2014:406960. doi: https://doi.org/10.1155/2014/406960

18. Elwan MM, Kishk NA, El-Kapany RA, Al-Ahmer IE, Elkady A. Serum level of C-reactive protein and interleukin-6 in children with drug-resistant epilepsy. Eur J Inflamm. 2018;16:1-6. doi: https://doi.org/10.1177/2058739218808165

19. Cui W, Kobau R, Zack MM, reporters. Among adults with epilepsy reporting recent seizures, one of four on antiseizure medication and three of four not on medication had not seen a neurologist/epilepsy specialist within the last year, the 2010 and 2013 US National Health Interview Surveys. Epilepsy Behav. 2016;61:78-9. doi: https://doi.org/10.1016/j.yebeh.2016.04.031

\section{Acknowledgements:}

To the Funds for the Incentive of Researches and Events (FIPE) of the Porto Alegre General Hospital.

\title{
- Corresponding author:
}

Marcia Koja Breigeiron

E-mail: mbreigeiron@gmail.com

\author{
Associate editors: \\ Aline Marques Acosta \\ Graziella Badin Aliti
}

